\title{
A longitudinal study of changeability in leisure meanings
}

\author{
Dr Mike Watkins, Griffith University
}

Leisure meanings can remain stable and change over time. However knowledge about the operation of meanings is generally limited to a single point in time or retrospective findings generated from cross-sectional research. This paper reports a longitudinal panel study that used a continuum of developmentally related meanings to investigate characteristics of change for a group of 35 Australian students' as they progressed through a three year leisure studies program and then five years after graduation. Results showed approximately two thirds of students changed meanings during the study and that meanings evolved in a logical progression from less to more developed understandings. The amount of change was relatively small, occurred early in the program or after graduation and was more evident for younger students with less developed meanings. Sources of change were related to educational and personal contingencies. The paper concludes by presenting several propositions about changeability in meanings and suggesting implications for further research.

Keywords: longitudinal research; leisure; meanings; epistemic development; change.

\section{Introduction}

Researchers have established that leisure meanings can remain stable and change over time. For example, studies comparing different age groups show that connotative meanings including doing something for pleasure or a respite from work, and properties of meanings such as freedom, enjoyment and relaxation, are consistently reported across age groups (e.g., Donald \& Havighurst, 1959; Kleiber, Caldwell \& Shaw, 1993; Shaw, 1985; Stockwell, 1986). Other studies highlight the dynamic quality of meanings by illustrating how entering a new life stage or performing different social roles influence our definitions of leisure (e.g., Carpenter \& Patterson, 2004; Dupuis \& Smale, 2000; Kelly, 1978; Rapoport \& Rapoport, 1975). Perhaps Freysinger (1987: p.12) best captures the complex operation of meanings with the observation that: "Not only does leisure mean the same and different things to different people; it also means different things to the same person.”

Nevertheless, several research issues continue to challenge our attempts to understand the nature of meanings. One issue is the prevalent use of cross sectional study designs and associated tendency of using socio-demographic 
variables as the basis for investigating difference and change in meanings.

Carpenter and Robinson (1990/2000), Henderson, Bialeschki, Shaw and Freysinger (1999), Kleiber (1999) and Osgood and Howe (1984) have variously argued the approach limits our ability to demonstrate actual evidence of stability and change by relying on a single point in time or retrospective description of meanings; to account for intra-individual perceptions of change or to determine characteristics including the magnitude and distribution of change. Despite calls for longitudinal research to redress the issue, few such studies have been reported; particularly in terms of attempts to systematically map quantitative features of changeability in meanings over time.

Longitudinal research, however, is not without its methodological difficulties. Problems identified by scholars such as Singer and Willet (2003) and Ployhart and Vandenburg (2010) include the need to deal with questions such as what represents an adequate number of occasions for collecting evidence of change, what is the optimal period of time between data collection periods to allow for the occurrence of change, how to deal with missing data and subject attrition, and how to ensure estimates of change are accurate and not related to errors associated with measurement and analytic biases. These questions are broadly linked to a second issue concerning the rigour of longitudinal designs. Given Pettigrew’s (1990: p. 268) assertion that studying change involves “catching reality in flight," considering these questions is important if the 'catch' is to be grounded in well designed research and the experience of subjective reality.

A third issue concerns the operational definitions of leisure meanings and change in meanings. In many studies, meanings are treated as dependant nominal 
variables and reported as collections of un-related connotative labels (e.g., as doing something for pleasure) or uni-dimensional properties (e.g., freedom and enjoyment) that vary in response to independent ordinal variables such as chronological age or life stage. This approach tends to position meanings as relatively passive and value neutral forms of knowledge, and represents change as the appropriation of a different meaning. An alternative view is to operationalise meanings as independent and ordinally related variables that characterise varying levels of epistemic development in understanding leisure. Defining meanings using this perspective encourages the possibility for specifying a set of interconnected meanings reflecting different capacities for how individuals understand or experience leisure and for researching how individuals might initially define and then subsequently evolve their meanings.

A fourth issue is the need to clarify the relationship between forms of change and whether leisure meanings evolve in a universal stage-like progression as proposed by some developmental theorists (e.g., Erikson 1962, Piaget, 1954) and/or whether change is more rapid and occurs along multiple trajectories as some post-modern theorists contend (see for instance discussions by Kleiber, 1999; Keuntzel, 2001). Qualitative evidence of longer term developmentally related change indicated by progression to a new meaning was reported by Kelly (1978) as people moved from a pre-parent to parental and then post parental roles. Carpenter and Patterson’s (2004) longitudinal case study of an older married couple showed the husband and wife's meanings altered in response to their transition from work to retirement. Situational change represented by short term shifts in meaning or returning to previously held meaning has also been identified. Lee, Dattilo and Howard (1994) noted people's interpretations of leisure could 
fluctuate whereby negative stressful memories reported immediately after participation altered several weeks later to positive exciting memories. Dupuis and Smale (2000) reported a study in which female care givers could experience formerly held meanings of leisure as the demands of their families health needs varied and subsequently restricted or increased carer’s access to leisure. However, further research into the operation of different forms of change is required to examine the alternative and often competing explanations for change.

In response to these issues and in keeping with the aim of this edition of Leisure Studies being directed toward research approaches that further our knowledge about leisure; this paper reports a longitudinal study of changeability in leisure meanings. Specifically, the study used a continuum of developmentally ordered meanings as the basis for mapping the location of individuals' understandings at four points in time over an eight year period, and for describing characteristics of changeability in meanings.

Research used to construct the continuum involved an exploratory qualitative investigation conducted with Australian leisure studies students (Watkins \& Bond, 2007) and a confirmatory study using non-leisure studies students (Watkins, 2008). These studies were based on a theoretical review of existing approaches to study leisure meanings and the elaboration of a phenomenographic approach framing the study of meanings within an educational and experiential context (Watkins, 2000). Two distinguishing propositions of phenomenography are that individuals learn new meanings when their awareness of relational dimensions forming the content of experiences alter as they acquire the ability to discern new relational values of dimensions, and that different experiences can be represented as a continuum of meanings demonstrating 
increasing levels of complexity or development in understanding (Marton \& Booth, 1997).

A set of categories and sub-categories describing six ways of experiencing leisure were reported from the exploratory and confirmatory studies. These were leisure as: passing spare or left over time (A), exercising choice by asserting control (B1), exercising choice by displaying one’s competence (B2), escaping pressure to forget about the problems of life (C1), escaping pressure to understand the problems of life (C2) and achieving feelings of happiness and fulfilment (D). These experiences were inter-connected by a set of dimensions describing relational variations in the meanings of the contexts, intentions, temporalities, emotions, and outcomes of experience. Interpretive judgements suggested some individuals' experiences represented more developed meanings than other individuals’ meanings. This was evidenced through the former individuals being able to express: (1) greater diversity in the relational meanings of dimensions, (2) more flexibility in the arrangement of dimensions in their awareness of leisure, (3) higher levels of integration between leisure and other aspects of life such as family and work, and (4) increasing inclusivity in the overall meaning of leisure through the ability to relate to previously held meanings. These judgements resulted in a continuum of meanings capturing different levels of understanding leisure and are illustrated in Figure 1. 


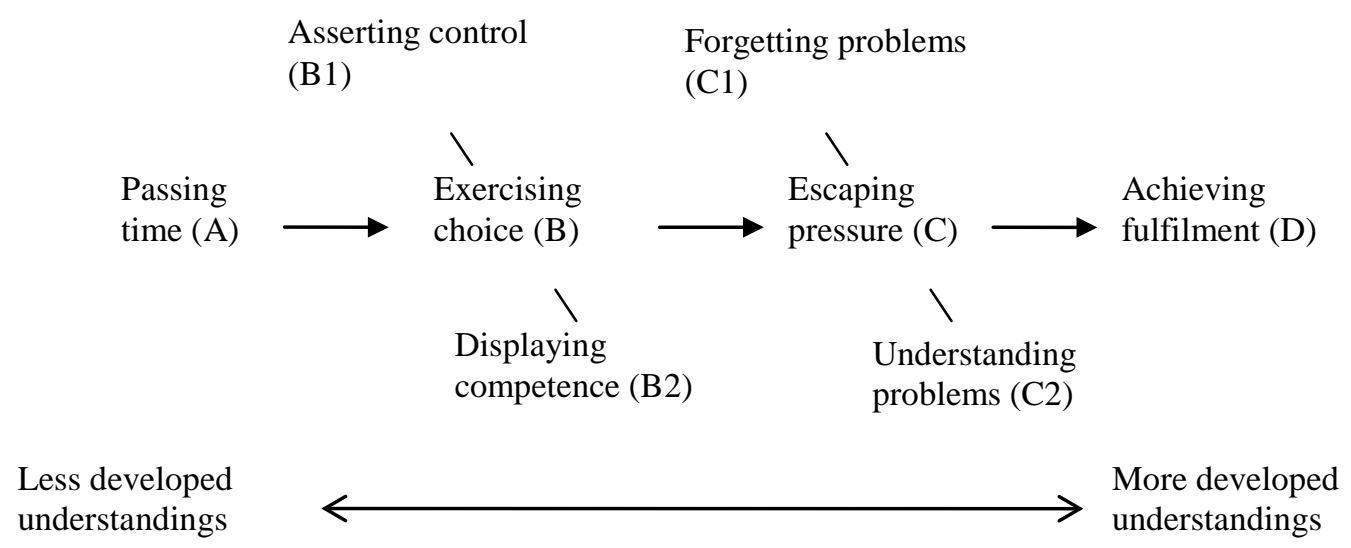

Figure 1. A continuum of development in leisure meanings

In light of the previous research, three questions framed the current study.

(1) To what extent do leisure meanings remain stable or change over time?

Given the existence of change and with elapsing time, do meanings evolve in the direction of more developed understandings as proposed in the continuum of meanings? And (3) what are the characteristics of change relative to its magnitude, timing, distribution, sources and outcomes?

\section{Study Methods}

\section{The Study Design}

A longitudinal panel design was employed to describe changeability in meanings using the cohort of leisure studies students identified previously. According to Menard (2002), panel designs can be prospective by collecting data at two or more separate points in time or retrospective by collecting data at one point in time for several periods. Prospective studies are more rigorous because they enable contemporaneous or in-situ assessments of data whereas retrospective studies rely on recall and are less rigorous because of the potential for bias resulting from memory decay. The present study was prospective as it measured students' meanings at four separate times over eight years and retrospective as 
students were periodically asked to recall information about their meanings from previous years. However as noted by Kleiber (1999), single cohort studies lack the power of studies using multiple cohorts, where change might be experienced differently by cohorts due to generational effects. The use of a single historically located cohort in the present research therefore represents a limiting factor with the study results.

\section{The Students and their Contexts}

Thirty five students formed the cohort for the study ${ }^{1}$. A proportionate random sampling procedure resulted in a cross-section of first year students, although most were from white Anglo middle class families (see Watkins \& Bond, 2007 for more detail). Over eight years, participation varied from 33 students in year 1, 24 in year 2, 16 in year 3 and 27 in year 8. Variation related to un-usable interviews caused by tape malfunctions ( $\mathrm{n}=2$ in year 1 ); students permanently dropping the course $(n=5)$, some deferring and then re-entering the course $(n=12)$, and others declining to continue participation $(n=1)$ or becoming deceased $(n=1)$. Further information about participation appears in the results section, however for the moment, two contextual factors are discussed for their possible impact upon students’ leisure meanings.

The first factor was student's exposure to a three year leisure studies program. Accreditation documents (Brisbane CAE, n.d: p.25) report the program was “designed as an academic process to examine the phenomenon of leisure from a multi-disciplinary perspective ... and teach recreation service delivery.” Three “developmental stages” framed the program. A foundation year included theory courses in the Philosophy, Psychology and Sociology of Leisure. These courses aimed to help students in their "analysis and re-evaluation of leisure 
understanding.” The second and third years taught professional skills (e.g., recreation programming), market sector specialisations (e.g., sport management), and industry practicum courses. Overall, the program provided 1,443 hours of formal learning, with about the same hours expected in private study. Thus with the explicit purpose of engaging students in a developmental process of learning about leisure, opportunities for students to consider and perhaps change their meanings were substantial.

The second factor was the influence of life events experienced by students during the study. The age of students in year 1 ranged from 17-38 years with an average of 20.5 years. Twenty of the 35 students were teenagers (17-19 years) when commencing the study. Eight years later, student ages ranged from 25-45 years with an average of 28.5 years. Most students therefore progressed from later adolescent to young adulthood life stage. Through-out the study, discussions about leisure were referenced by students to a variety of mundane and significant events in their previous, current and anticipated lives. In the first three years, younger students often expressed a sense of anxious optimism; the idea of being not quite ready to forego the relative freedom of adolescence and the emotional security of the family home and parent's financial support, while concomitantly looking forward to greater independence, establishing their own living space, and finding a satisfying career. Some older students expressed a similar feeling. Many had left paid work to acquire new qualifications and careers, and were anxious about whether they had made the right choice. Learning to study and socialise with younger students intensified their concerns. However, opportunities for intellectual stimulation and space for reflection were cause for optimism. By year 8, many but not all students, reflected a broader range of life 
experience and greater self-confidence. Most students had therefore encountered significant personal change and expressed more awareness of how their experiences and understandings of leisure had responded to or enabled these changes.

\section{Data Collection}

Four interviews obtained information about meanings; the first conducted before most students commenced their studies, the second at the end of second year, the third at the end of their final year, and the fourth interview five years after graduation $^{2}$. The number of interviews and the timing of interviews relative to students’ academic study and subsequent transition to working life helped maximise the potential for eliciting the extent and characteristics of change.

Four researchers conducted interviews in year 1 and 2, two in year 3 and one in year 8. Three of the researchers had no direct involvement in teaching students, which limited the possibility for self presentation of ideas by researchers during interviews. Face to face interviews were used in years 1 to 3 and telephone interviews in year 8 . The latter procedure was required to negotiate around students’ family and work schedules, and by some students having moved intrastate $(n=12)$, inter-state $(n=1)$ or overseas $(n=3)$.

Interviews commenced with sensitising questions informing students about the study and to build report and commitment. This strategy was important to maintain participation and reduce attrition during the study (Carpenter \& Robertson, 1999/2000). These questions were followed by asking for examples of leisure and probing responses to find out what it was about the experiences that made them leisure (see Watkins \& Bond, 2007 for more detail). Retrospective questions in year 3 and 8 asked students whether their meanings had changed, and 
if so, what changed and why. In year 8 , students were asked to review descriptions of meanings reported in Watkins and Bond and say which meaning/s best fitted their understanding/s. This procedure further clarified meanings and provided an opportunity for students to check the researcher's categorisations of meanings. It is important to note this procedure was conducted by giving students verbal descriptions of the four categories of meanings. Attempts to explain the detail and distinctions between the sub-categories of exercising choice and escaping pressure proved difficult for many students via telephone and were discontinued. Thus verbal phone descriptions of meanings may have limited students' abilities to accurately respond to the researcher's questions. A total of 100 interviews were recorded with each interview averaging six pages and including three different examples of leisure. These procedures resulted in approximately 600 pages of transcript and 300 examples of leisure.

\section{Data Analysis}

Analysing the longitudinal data to study changeability was achieved using the continuum of meanings to assign students to one meaning for each year they completed an interview and to compute frequencies and percentages to quantify the results. Prior to assigning students to meanings, a rule was established to allocate students to a particular meaning for a particular year according to the most complete or developed meaning evident in their interviews for the year in question. Inspection of transcripts showed some students expressed a single meaning for a particular interview, in some cases two meanings, and in other cases parts of several meanings. Marton, Beatty and Dall'Alba (1993) used a similar procedure in their longitudinal study of change in student learning. 
An additional consideration was how to deal with three students who expressed the most developed leisure meaning (achieving fulfilment, D) in years 1 to 8. Employing the rule described above, in conjunction with the developmental assumptions inherent in the continuum of meanings, meant it was unlikely for these students to show evidence of change - a situation corroborated by their perceptions of not changing their meanings during the study. Including the students might skew the results given the relatively small study sample. This issue was resolved by distinguishing these students in some analyses and to report single and averaged measurements in order to provide more conservative and accurate assessments of meanings.

Procedures for calculating characteristics of meanings are reported in the results section to assist with understanding how the various quantitative assessments were made. As will be noted, these procedures highlighted several challenges with quantifying meanings.

\section{Results and Discussion}

Results are presented and discussed in two sections. The first section considers the trustworthiness of the longitudinal data relative to factors that might detract from or enhance the study results (e.g., missing interviews and differences between researcher and student assessment of meanings). The second section reports evidence about changeability in meanings. Both sections summarize data from Tables 1 and 2 below.

\section{Indicators of Data Trustworthiness}

As previously indicated, student participation varied during the study. Retention rates were $72.2 \%$ from year 1 to $2,66.7 \%$ from year 2 to 3 , and $59.5 \%$ from year 3 to 8. Although the decline from year 1 and 3 was around 50\%, the overall 
retention of students from year 1 to 8 was $82 \%$. Given difficulties maintaining subjects in longitudinal studies (Saldana, 2003), this indicator represents a satisfactory result. This judgement needs to be weighed against the number of interviews completed by individual students. If four interviews per student represented the maximum condition for measuring changeability, then only 14 students (42.4\%) met the condition. This number declines to 11 (or 33\%) when excluding the three students with the most developed meaning discussed previously. However, twenty-one students (63.6\%) completed at least three interviews and 30 from a possible 35 students (90.9\%) achieved the minimum condition by completing at least two interviews.

These indicators were extended by estimating correspondence between researcher and student categorisation of meanings, and change in meanings. A visual comparison of researcher determined meanings for years 1 to 8 and student determined meanings in year 8 in Table 1 shows the researcher's assessment of meanings generally corresponded to students’ assessments. A quantitative assessment of correspondence was obtained by comparing the researcher's determination of students most developed meaning in year 8 with student's determination of their most developed meaning also made in year 8. This comparison revealed that out of 27 possible cases, there were19 cases of agreement (70.4\%) and eight cases of disagreement (29.6\%). Disagreement occurred for seven students who perceived they had a more developed meaning than determined by the researcher, and for one student who perceived a less developed meaning.

Estimating the degree of correspondence for change in meanings between the researcher and students was perhaps the most important of all indicators given 
the study focus and the subjective nature of categorisation processes. In Table 1, the last column reports student's assessment of whether they experienced change between years 1 and 3 and years 3 and 8; recorded as a yes, no or missing response. An equivalent estimate, although not apparent in Table 1, was calculated by comparing the researcher's categorisation of change between years 1 and 3 , years 3 and 8 , and years 1 and 8 . Applying this procedure showed that in year 1 to 3, out of 15 possible cases there were nine cases of agreement (60\%) and six disagreements (40\%). This result suggested a moderate level of correspondence for this time period. However from years 3 to 8 there were 27 cases made up of 22 agreements (81.5\%) and five disagreements (18.5\%), which indicated a markedly higher degree of correspondence. The result for years 1 to 8 revealed 42 possible cases with 31 cases of agreement (73.8\%) and 11 disagreements (26.2\%).

In terms of the trustworthiness of the data, the overall retention rate of $82 \%$ in combination with the $91 \%$ of students completing two or more interviews suggest the study results can be considered with a reasonable level of confidence. The average correspondence estimate for leisure meanings and for change in meanings between the researcher and students of $72 \%$ further supported this claim. Notwithstanding, however, variations in interviews completed by students and categorisations between the researcher and students, reinforced the need to provide multiple measures of changeability to overcome these variations. 


\begin{tabular}{|c|c|c|c|c|c|c|c|}
\hline \multirow{2}{*}{$\begin{array}{l}\text { Student } \\
\text { name }\end{array}$} & \multirow[b]{2}{*}{ Age } & \multicolumn{4}{|c|}{$\begin{array}{c}\text { Researcher's categorisation of student } \\
\text { meanings }{ }^{1}\end{array}$} & \multirow{2}{*}{$\begin{array}{c}\text { Students' } \\
\text { categorisations of } \\
\text { their meanings in } \\
\text { year8 }{ }^{2} \\
\end{array}$} & \multirow{2}{*}{$\begin{array}{c}\text { Students' } \\
\text { perceptions of } \\
\text { change in } \\
\text { year3/year8 }\end{array}$} \\
\hline & & year 1 & year 2 & year 3 & year 8 & & \\
\hline Sian & 19 & A & & & & & \\
\hline Carl & 17 & $\mathrm{~A}$ & & & & & \\
\hline Ann & 18 & $\mathrm{~A}$ & A & & & & \\
\hline Ben & 17 & A & & & $\mathrm{C} 1$ & $\mathrm{~A}, \mathrm{C}$ & -/Yes \\
\hline David & 17 & $\mathrm{~A}$ & B1 & B1 & B1 & $\mathrm{A}, \mathrm{B}$ & $\mathrm{No} / \mathrm{No}$ \\
\hline Darryl & 17 & A & B1 & B2 & $\mathrm{C} 2$ & $\mathrm{~A}, \mathrm{~B}, \mathrm{C}$ & Yes/Yes \\
\hline Millie & 18 & B1 & & & & & \\
\hline Keas & 19 & B1 & & & & & \\
\hline Giles & 18 & B1 & B1 & & & & \\
\hline Jules & 19 & B1 & & & C1 & $\mathrm{B}, \mathrm{C}$ & -/Yes \\
\hline Joan & 19 & & B1 & & B1 & $\mathrm{B}, \mathrm{D}$ & -/No \\
\hline Eleanor & 19 & B1 & B1 & & C1 & $\mathrm{B}, \mathrm{C}$ & -/Yes \\
\hline Wynita & 19 & B1 & B1 & & $\mathrm{C} 2$ & $\mathrm{~B}, \mathrm{C}$ & -/Yes \\
\hline Ruth & 17 & B1 & B1 & & $\mathrm{C} 2$ & $\mathrm{~B}$ & -/No \\
\hline Amy & 18 & B1 & B1 & B1 & $\mathrm{C} 1$ & $\mathrm{~A}, \mathrm{C}, \mathrm{D}$ & Yes/Yes \\
\hline Naomi & 18 & B1 & B1 & B1 & C1 & $\mathrm{B}, \mathrm{C}$ & No/Yes \\
\hline Marie & 19 & B1 & $\mathrm{C} 1$ & $\mathrm{C} 1$ & $\mathrm{C} 2$ & $\mathrm{~B}, \mathrm{C}$ & Yes/Yes \\
\hline Bob & 19 & & B2 & B2 & $\mathrm{C} 2$ & $\mathrm{~B}, \mathrm{C}$ & -/Yes \\
\hline Jack & 18 & B2 & & & C2 & C & -/Yes \\
\hline Catriona & 18 & B2 & & & C2 & $\mathrm{B}, \mathrm{C}$ & -/Yes \\
\hline Kylie & 18 & B2 & B2 & & C2 & $\mathrm{A}, \mathrm{C}$ & -/Yes \\
\hline Dom & 20 & B2 & B2 & B2 & C2 & $\mathrm{A}, \mathrm{B}, \mathrm{C}, \mathrm{D}$ & Yes/Yes \\
\hline Katrina & 26 & B2 & $\mathrm{C} 2$ & $\mathrm{C} 2$ & $\mathrm{C} 2$ & $\mathrm{~A}, \mathrm{~B}, \mathrm{C}$ & Yes/No \\
\hline Louise & 19 & B2 & $\mathrm{B} 2$ & & $\mathrm{C} 2$ & $\mathrm{~A}, \mathrm{~B}, \mathrm{C}, \mathrm{D}$ & -/Yes \\
\hline James & 24 & $\mathrm{~B} 2$ & $\mathrm{~B} 2$ & $\mathrm{C} 2$ & $\mathrm{C} 2$ & $\mathrm{~A}, \mathrm{~B}, \mathrm{C}, \mathrm{D}$ & No/No \\
\hline Margaret & 22 & $\mathrm{C} 1$ & C1 & C1 & & & Yes/- \\
\hline Mary & 19 & C1 & C1 & C1 & C1 & $\mathrm{B}, \mathrm{C}$ & Yes/No \\
\hline Glen & 23 & C1 & C1 & C1 & C1 & $\mathrm{B}, \mathrm{C}$ & Yes/Yes \\
\hline Derek & 20 & C1 & C2 & $\mathrm{C} 2$ & $\mathrm{D}$ & C, D & Yes/No \\
\hline Sophie & 20 & C1 & & & $\mathrm{C} 2$ & $\mathrm{~B}, \mathrm{D}$ & -/Yes \\
\hline Helen & 23 & $\mathrm{C} 2$ & & & & & \\
\hline Damien & 26 & $\mathrm{C} 2$ & & & $\mathrm{C} 2$ & $\mathrm{~A}, \mathrm{~B}, \mathrm{C}, \mathrm{D}$ & -/Yes \\
\hline Brigit & 38 & $\mathrm{D}$ & $\mathrm{D}$ & $\mathrm{D}$ & $\mathrm{D}$ & $\mathrm{B}, \mathrm{C}, \mathrm{D}$ & $\mathrm{No} / \mathrm{No}$ \\
\hline Matt & 28 & $\mathrm{D}$ & $\mathrm{D}$ & $\mathrm{D}$ & $\mathrm{D}$ & $\mathrm{A}, \mathrm{D}$ & No/No \\
\hline Peter & 25 & $\mathrm{D}$ & $\mathrm{D}$ & $\mathrm{D}$ & $\mathrm{D}$ & $\mathrm{A}, \mathrm{B}, \mathrm{C}, \mathrm{D}$ & No/No \\
\hline Total & & 33 & 24 & 16 & 27 & & \\
\hline \multicolumn{8}{|c|}{$\begin{array}{l}\text { Notes: }{ }^{1} \mathrm{~A}=\text { =Passing Time, B1=Exercising Choice by Asserting Control, B2=Exercising Choice to } \\
\text { Display One's Competence, C1=Escaping Pressure by Forgetting Problems, C2=Escaping Pressure to } \\
\text { Understand Problems, D=Achieving Fulfilment. }{ }^{2} \text { Students could nominate one or more meanings. A } \\
\text { blank cell indicates a damaged tape, a student deferred, departed the course, declined to be interviewed, } \\
\text { or became deceased during the study. }\end{array}$} \\
\hline
\end{tabular}

\section{Extent of Stability and Change in Meanings}

Three measures based on the researcher's assessment of students' meanings

estimated the extent of changeability. An overall measure counted the total 
number of possible occasions where two or more interviews were conducted with the same student irrespective of the years in which interviews occurred. This procedure indicated that out of 65 occasions, there were 41 instances of no change (62.1\%) and 24 instances of change (37.9\%). Excluding the three students with the most developed meaning resulted in fewer occasions of change $(n=56)$; reduced the percentage of no change to $57.1 \%$ and increased the percentage of change to $42.9 \%$. At the most general and inter-individual level of analysis, there was more stability than change in meanings with an averaged ratio of 60/40.

However this situation reversed significantly at the level of intraindividual analysis. The second measure counted students completing interviews in year 1 and again in year 8 . From 25 students, 19 were recorded as having changed meanings (76\%) and six as not changing meanings (24\%). Leaving out the three students increased the percentage of change to $86.3 \%$ and decreased no change to $13.6 \%$. By taking both measures into account, the averaged ratio of stability to change altered to around 20/80.

The third and arguably more rigorous measure examined students completing all four interviews. Including the three students showed that of 14 students, nine changed meanings (64.3\%) and five were determined as not changing (35.7\%). Excluding the three students significantly altered the percentage of change upwards to $81.8 \%$ and no change downwards to $18.2 \%$. This procedure altered the averaged ratio to around 30/70.

These measures were complemented using student assessments of changeability. Of 15 students interviewed in year 1 and in year 3, nine said they experienced change (60\%) and six reported no change (40\%). Five years later, 18 of 27 students said their meanings had changed since graduation (66.7\%) with 
nine perceiving no change (33.3\%). Student responses about change recorded as yes and no statements, however, fail to illustrate the diversity of responses. For instance, responses ranged from: “yes, my meaning has definitely changed” to “yes some parts of my meaning have changed” to “I honestly can’t recall, I’m not certain,” and to “no, they haven’t changed.” Bearing in mind this diversity, an average of student perceptions indicated a ratio of stability to change at 40/60.

To sum up, inter-individual assessments determined by the researcher highlight more evidence of stability in meanings. Other scholars have reported a similar conclusion (e.g., Henderson, et al., 1999; Kleiber, 1999). Focusing on individuals however, reflects more change, as do individuals own assessments of change. A net (averaged) figure suggests that for students in this study, approximately two thirds changed their meanings over eight years and one third experienced no change.

\section{Forms of Change in Meanings}

The possibility for change to be developmentally related was indicated by measuring student's progression from less to more developed understandings using the continuum of meanings. Inspection of Table 1 shows that 20 out of 22 students changed to more developed understandings of leisure by the end of the study. (This figure excludes the three D students and two others with missing interviews in year 1). In addition, the number of students categorised with the most developed meanings (e.g., escaping pressure and achieving fulfilment) more than doubled during the study ( $\mathrm{n}=10$ in year $1, \mathrm{n}=25$ in year 8$)$.

Table 1 also revealed many students' meanings for particular years clustered with immediately preceding or subsequent meanings as illustrated in the continuum. Two recurring clusters or patterns of development were evident: 
change from (B2) exercising choice by displaying competence to (C2) escaping pressure by understanding problems $(\mathrm{n}=9)$, and change from (B1) exercising choice by asserting control to (C1) escaping pressure by forgetting about problems $(\mathrm{n}=5)$. Change between sub-categories appears minimal (e.g., B1 to B2 and C1 to $\mathrm{C} 2, \mathrm{n}=3$ ), but the figure is likely to be underestimated given the categorisation process and evidence from the Watkins and Bond (2007) study about the prevalence of movement across sub-categories. Change across other combinations of meanings were few or non-existent (e.g., from B1 to C2, n=2; from A to D, $\mathrm{n}=0$ ). Importantly, these measures collectively support the existence of developmental change in meanings and confirm the interpretive judgements made by Watkins and Bond and Watkins (2008) about the direction of epistemological development proposed in the continuum of meanings.

The two patterns of development suggest the meanings are ordinally related but not in a strictly invariant and universal fashion as posited by hard stage 'classical' models reported in the developmental psychology literature. This is because the four sub-categories appear to provide opportunity for 'switching' or progressing along different paths of development. Moreover, differences in development may relate to student characteristics where students representing change from B1 to $\mathrm{C} 1$ reflect an external or other directed orientation and the students changing from B2 to C2 an internal self directed orientation. This characteristic was noted by Watkins and Bond (2007). Subsequently, the nature of developmental change framing the continuum of meanings may be more consistent with a soft stage model that allows for intermediate or alternative paths of development within the same basic framework rather than a hard stage universal model (cf., Kohlberg \& Armon, 1984). 
Evidence of situational change was mitigated by the rule for assigning students to one particular meaning for each interview occasion. An ideal measure would count actual instance of change with reference to previously held meanings. However, this was not possible and so a retrospective count was extrapolated from student discussions.

When asked to identify which meaning/s they could relate to in year 8, 25 out of 27 students said they recognised more than one meaning as being related to their understanding of leisure. Sixteen related to two meanings; four students to three meanings, and five students to four meanings. Many of the latter students also expressed more developed understandings of leisure by the end of the study. This is important in the sense that these students would be expected to have learned more meanings compared with students with less developed understandings, and to be therefore capable of recognising a broader array of meanings within their situational awareness of leisure.

Additional evidence came from discussions about how students understood change in their meanings. Fifty-five comments drawn from discussions revealed four themes. Twenty-three comments (41.8\%) indicated students could experience a combination or overlap in meanings (e.g., "I experience a range of them, they all struck a chord” or "I can relate to exercising choice, a bit of escaping pressure, a mix really”). Only eight comments (14.4\%) referenced experiencing a single or dominant meaning (e.g., "I probably only end up seeing leisure in one way”). Eleven comments (20.0\%) linked meanings to longer developmental term changes in life stage (e.g., "my meanings have changed since I was younger”), while 13 comments (23.6\%) related meanings to 
recent current circumstances (e.g., "escaping pressure is the position I am stuck in at moment, but it changes”).

The measures and comments described above provide relatively strong evidence for developmental change in meanings and somewhat weaker circumstantial evidence of situational change. Nevertheless, there appears to be a dialectical relationship between the two forms of change that operate simultaneously. How this relationship actually plays out was not particularly apparent in the results, although a tentative explanation taking account of student comments might be as follows: students evolve their developmental understandings of leisure consistent with their broader personal development but maintain a link with previously learned meanings that in turn become part of their situationally dependent repertoire of understandings. On this account, situational change is not likely to be as random as suggested in some post modern accounts (see for instance discussion by Rojek, 1995), but operates within a logical overarching structure of developmental change.

\section{Characteristics of Change in Meanings}

\section{Magnitude of Change}

The magnitude or size of change measured how much change in meanings occurred during the study period and was determined by the number of 'meaning spaces' students moved along the continuum of meanings. The smallest change would be represented by movement of one meaning space (e.g., from A to B1 or from C1 to C2). Larger changes would be represented by movement across two or more meanings spaces (e.g. from A to B1 to C1 = 2 meanings spaces or from $\mathrm{B} 1$ to $\mathrm{C} 1$ to $\mathrm{C} 2$ to $\mathrm{D}=3$ meanings spaces). 
Of students completing two or more interviews, 16 of 27 students changed one meaning space, three students changed two meaning spaces, and one student changed three meaning spaces. Single movements were from A to B1 (n=2), B1 to $\mathrm{C} 1(\mathrm{n}=5), \mathrm{B} 1$ to B2 $(\mathrm{n}=1)$ B2 to C2 $(\mathrm{n}=9), \mathrm{C} 1$ to $\mathrm{C} 2(\mathrm{n}=2)$, and C2 to $\mathrm{D}(\mathrm{n}=1)$. These findings indicate the overall size of change was relatively small and incremental over eight years. This is not particularly surprising given the developmental qualities of meanings and the fact that changeability was measured across one life stage from adolescence to young adulthood.

\section{Timing of Change}

Researcher categorisations and student perceptions of when change occurred were determined by counting instances of change during the academic program and after graduation. The researcher estimates of change reported in Table 1 indicated six out of 20 students (30\%) changed meanings during their academic studies and six out of 13 students (46.2\%) changed after graduation. In the case of change during the program, more instances occurred between years 1 and 2 when students where exposed to leisure theory courses than between years 2 and 3 when the program became professionally based. Student perceptions of change indicated nine out of 15 students (60\%) changed meanings between years 1 and 3, and 17 out of 24 students (70.8\%) changed meanings after graduation.

While acknowledging considerable differences between the researcher and student assessments, an average of their assessments indicated $45 \%$ of change was recorded during the program and $58.5 \%$ after graduation. In overall terms, the influence of a substantial leisure education program on change in meanings appears to be less noticeable compared with the influence of five years of subsequent life and work experience. 


\section{Distribution of Change}

Information about the distribution of change identified which individuals changed meanings. This characteristic was described by synthesising student's gender and age, and number of changes experienced during the study. Students initially assigned to passing time $(\mathrm{A}, \mathrm{n}=4)$ were mostly male, averaged 17.3 years in age and recorded 5 out of 8 possible changes. Students assigned to exercising choice by asserting control (B1, $\mathrm{n}=9$ ) were predominantly female, averaged 18.4 years and recorded 8 out of 18 changes. Students categorised as exercising choice by displaying their competence (B2) consisted of equal numbers of females and males, averaged 20.3 years and recorded 7 out of 17 changes. Students escaping pressure to forget about problems $(\mathrm{C} 1, \mathrm{n}=5)$ were also equally distributed among genders; were a few months older (average age $=20.8$ years) and experienced significantly fewer changes in meaning (3 out of 12 changes). One older male student (20.6 years) represented escaping pressure to understand problems (C2) and recorded no change in meanings as did three students (one female and two males) experiencing leisure as achieving fulfilment (average of 30.3 years).

Younger students with less developed meanings therefore demonstrated greater amounts and hence different rates of change relative to older students with more developed meanings. Students experiencing the B1 and C1 sub-categories of exercising choice and escaping pressure, and who were mostly female, averaged the least change of all students. This finding may reflect their more difficult personal circumstances and perhaps the effects of gender where many of the pressures were connected with role determined caring responsibilities. These findings constitute evidence of regularity in change for some groups of students, although individual differences are apparent for other students. 
Sources and Outcomes Associated with Change

Sources and outcomes of change in meanings were measured at the end of years 3 and 8 (see Table 2).

Table 2. Factors associated with change in leisure meanings

\begin{tabular}{|c|c|c|c|c|}
\hline & \multicolumn{2}{|c|}{ year $3(n=16)$} & \multicolumn{2}{|c|}{ year 8 (n=27) } \\
\hline & $\mathrm{f}$ & $\%$ & $\mathrm{f}$ & $\%$ \\
\hline \multicolumn{5}{|l|}{ Sources of change } \\
\hline Leisure theory courses & 13 & 40.6 & 1 & 3.2 \\
\hline Practical leisure courses & 7 & 21.9 & 1 & 3.2 \\
\hline Talking to others about leisure & 4 & 12.5 & & \\
\hline Work/family situation & 1 & 3.1 & 9 & 29.0 \\
\hline Less time/more stress & 2 & 6.3 & 12 & 38.7 \\
\hline Growing older/more mature & 5 & 15.6 & 8 & 25.8 \\
\hline Total & 32 & 100.0 & 31 & 100.0 \\
\hline \multicolumn{5}{|l|}{ Outcomes of change } \\
\hline Type/frequency of activities changed & 3 & 12.5 & 6 & 15.7 \\
\hline Have a broader view of leisure & 9 & 37.5 & 8 & 21.1 \\
\hline Can better reflect on leisure & 7 & 29.2 & 10 & 26.3 \\
\hline More appreciation of leisure's value & 3 & 12.5 & 4 & 10.5 \\
\hline Need to plan or design leisure & 2 & 8.3 & 10 & 26.3 \\
\hline Total & 24 & 100.0 & 38 & 100.0 \\
\hline
\end{tabular}

Six sources or reasons for change were identified. Three related to the leisure studies program: knowledge from leisure theory subjects and professional subjects (e.g., "I related to leisure as a state of mind definition because I can sometimes 
find leisure in my work”), and learning from talking with others (e.g., “discussions with other students outside class helped me think about what leisure is for me”). Three additional non-program sources were: changes in students' work/family situations (e.g., "I have different responsibilities now I work fulltime”), having less time/feeling more stress (e.g., "I have much less time and lots of external pressures”) and maturing as a person (e.g., “I’m more self aware” or "I’ve grown up and see things differently from when I was younger”). Program sources accounted for $75 \%$ of student responses in year 3 with theory and professional subjects considered the most influential (40.6\% and 21.9\% respectively). Five years after leaving university, non-program sources comprised around $94 \%$ of student responses with work, family and time pressures being most dominant.

Five outcomes or consequences were associated with change in meanings. In year 3, 37.5\% of students mentioned acquiring a broader view of leisure (e.g., “I have a wider perspective and see leisure differently”), followed by $29 \%$ who noted a more developed ability to reflect about leisure (e.g., "I have learned to think about what's going on in my life and how leisure relates to this”). Change in activities (e.g., "I play less sport and do more passive activities”) was identified by $12.5 \%$ of students, while the same proportion valued leisure more highly (e.g., “I can now see its importance to me and other people”). The need to plan time and design effective leisure experiences were noted by around 8\% of students. In year 8 this latter outcome tripled in importance for students. Most other outcomes remained consistent relative to their influence in year 3.

Sources and outcomes of change highlight the interplay of factors students attributed to change in meanings. Two findings are particularly noteworthy. The 
first is the sources derived from studying leisure do appear to precipitate change in meanings, despite the previous contrary suggestion. The second finding is the sources may have a residual effect through students acquiring a broader view, greater appreciation and reflective capacity for understanding leisure, given these outcomes held constant after graduation. These sources and the outcomes they produce may therefore serve as important enabling conditions for further development of meanings. However, these findings do not overshadow the comparatively greater influence of immanent and contingent sources such as access to time for leisure and levels of stress, along with the constant longer term effects of ageing and maturity.

\section{Conclusions}

This study used a continuum of meanings reflecting different levels of epistemological development in individuals' understandings of leisure to make longitudinal quantitative assessments of changeability in meanings. Several conclusions emerge from these assessments in relation to the research questions and suggest implications for further research into leisure meanings.

Firstly, there was less evidence of stability and more evidence of change in the meanings for the students investigated in this study. In respect to this conclusion, it is worth noting that different procedures for determining changeability in meaning produced different outcomes. While these outcomes were expressed as simple frequency ratios, they nonetheless demonstrate the potential for over or under-reporting the actual extent to which individuals can be assessed as not changing or as having changed meanings. An implication from this conclusion reinforces the need for researchers to consider using multiple measures to gauge the extent of changeability in meanings. 
A further implication highlights the value of operationalising meanings as a continuum of ordinal experiences emphasising progression in understanding leisure. The approach used in the study when combined with longitudinal design, enabled the researcher to locate students' meanings at different points in time and at different epistemic stages relative to other possible meanings and to subsequently discriminate the existence and characteristics of changeability. This approach therefore provides a viable and perhaps more sensitive method for studying the dynamic qualities of meanings compared with approaches that treat meanings as nominal and (often) un-related understandings.

A second conclusion is the longitudinal data confirmed the direction of development in understanding proposed in the continuum of meanings across the categories and sub-categories of experience. For most students, meanings evolved from less to more developed understandings as they were exposed to a leisure education curriculum and an ensuing period of five years of life and work experience. This conclusion is consistent with the idea that knowledge about leisure can be acquired through gaining experiences from formal and informal sources of learning. It is particularly interesting to note, however, that despite these experiences; comparatively few students acquired the most developed meanings represented in the continuum. The implication from this conclusion is that while students' meanings appear to accumulate with experience; the ability of controllable interventions (e.g., leisure education programs) to broaden and extend student understanding cannot be taken for granted. While no attempt was made to associate the effectiveness of particular teaching/learning strategies with gains in students' understandings of leisure in the present study, it would be a useful and important area of further research. Nonetheless, the continuum of meanings may 
provide educators and policy makers with a heuristic device on which to establish educational programs and social policies that facilitate more developed understandings of leisure.

A third conclusion can be drawn from a synthesis of findings about characteristics of changeability in meanings, and is presented as three theoretical propositions for how change appears to operate for the students investigated in this study.

(1) Students' leisure meanings appear to follow a logical pattern of evolution where change occurs from less to more developed understandings of leisure. However, change is also likely to be differentially distributed whereby students evolve their understandings at different rates and times, and in response to different educational and personal contingencies.

(2) Students may experience periods of stability in meaning where a developmentally dominant meaning pervades their awareness of leisure, and periods of situational change, where they bring forth other previously learned meanings in response to immediate contingencies.

(3) When students express particular meanings, their understandings of leisure are likely to reflect aspects of meanings experienced in the past and aspects of subsequent meanings partially or yet to be fully grasped. Meanings can be thus thought of as containers representing students' capacities for recapitulating their past lives and realising their future possibilities.

Given the findings in this study were derived from a narrowly defined cohort of subjects; the conclusions drawn from these findings may not be generalisable to other cohorts. Furthermore, while the conclusions were generated from quantitative estimates of changeability, case studies focusing on individuals exhibiting different patterns or trajectories of change in meanings would permit more detailed analyses of how change occurs and of the particular factors that might explain the process of transformation between different meanings. To the extent this knowledge would further our ability to enhance individual well-being, the longitudinal research used in the present study provides empirical evidence that individuals can learn to acquire more developed ways of experiencing leisure than they were hitherto capable of understanding. 


\section{Notes}

${ }^{1}$ The the word student/s is used for ease of reference even though individuals moved from being students to graduates after completing the degree. Given the study's educational context, individuals can be considered students irrespective of whether they are engaged in formal institution based learning or informal lifelong learning.

${ }^{2}$ While all students commenced the course in the same year and were interviewed within a few weeks prior to or commencing year 1 ; several students deferred their studies at different stages during the program and therefore graduated in different years. Hence, with the exception of year 1 interviews, the timing of year, 2, 3 and 8 interviews varied slightly to match students' years of enrolment and graduation.

\section{Notes on Contributor}

\section{References}

Brisbane C.A.E. (n.d). A review of the Bachelor of Recreation Management. School of Physical Education and Leisure Studies. Brisbane, Australia.

Carpenter, G. \& Patterson, I. (2004). The leisure perceptions and leisure meanings of a mid-life couple around the time of retirement. World Leisure Journal, 46(2), 13-25.

Carpenter, G., \& Robertson, B. (1999/2000). A call for the increased use of longitudinal methods in research on adult leisure. Leisure/Loisir, 24 (1-2), 59-87.

Donald, M., \& Havighurst, R. (1959). The meanings of leisure. Social Forces, 355-360.

Dupuis, S.L., \& Smale, B.J. (2000). Bittersweet journeys: Meanings of leisure in the institution-based care giving context. Journal of Leisure Research, 32 (3), 303-340).

Erikson, E. (1962). Childhood and society. New York: Norton.

Freysinger, V.J. (1987). Leisure in middle adulthood: A developmental study. Journal of Physical Education, Recreation and Dance, 58(8), 40-45.

Kelly, J.R. (1978). Family leisure in three communities. Journal of Leisure Research, 10 (1), pp.47-60.

Kleiber, D. (1999). Leisure experience and human development: A dialectical interpretation. New York NY: Basic Books.

Kleiber, D., Caldwell, L., \& Shaw, S. (1993). Leisure meanings in adolescence. Society and Leisure, 16 (1), 99-114.

Kohlberg, L., \& Armon, C. (1984). Three types of stage models used in the study of adult development. In M.L. Commons \& C. Armons. (Eds.), Beyond formal operations (p.383-394). New York: Praeger.

Kuentzel, W.F. (2001). How specialized is specialization? Journal of Leisure Research, 33, (3), 351-356.

Lee, Y., Dattilo, J., \& Howard, D. (1994). The complex and dynamic nature of leisure experience. Journal of Leisure Research, 26, (3), 195-212.

Menard, S. (2002). Longitudinal research. ( $2^{\text {nd }}$ ed).London: Sage.

Marton, F., \& Booth, S. (1997). Learning and awareness. New Jersey: Erlbaum Publishing.

Marton, F., Beatty, S., \& Dall’Alba, G. (1993). Conceptions of learning. International Journal of Educational Research, 19, 277-300.

Pettigrew, A. M. (1990). Longitudinal field research on change: Theory and practice. Organisational Science, 1, (3), 267-292.

Piaget, J. (1954). The construction of reality in the child. New York: Bass Books. 
Ployhart, R. E. \& Vandenburg, R. J. (2010). Longitudinal research: The theory, design and analysis of change. Journal of Management 36 (1), 94-120.

Rapoport, R. \& Rapoport, V. (1975). Leisure and the family lifecycle. London: Rutledge and Keegan.

Rojek, C. (1995). Decentring leisure: Rethinking leisure theory. London: Sage.

Saldana, J. (2003). Longitudinal qualitative research: Analysing change through time. Walnut Creek, CA: Alta Mira.

Shaw, S. (1984). The meaning of leisure in everyday life. Leisure Sciences, 7 (1) $1-24$.

Singer, J D. \& Willet, J. B. (2003). Applied longitudinal analysis. New York: Oxford University Press.

Stockdale, J. (1985). What is leisure? An empirical analysis of the concept of leisure and the role of leisure in peoples' lives. London: Sports Council.

Watkins, M. (2000). Ways of learning about leisure meanings. Leisure Sciences, 22, 93-107.

Watkins, M. \& Bond, C. (2007). Ways of experiencing leisure. Leisure Sciences. 29 (3) 287-307.

Watkins, M. (2008). A confirmatory study investigating different ways of experiencing leisure. Annals of Leisure Research. 11, (1\&2) 205-225. 